\title{
Comparison of Two Analytical Methods for the Determination of Traces of Veterinary Antibiotics and Steroid Hormones in Soil Based on Pressurised Liquid Extraction (PLE) and Quick, Easy, Cheap, Effective, Rugged, Safe (Modified-Quechers) Extraction
}

\section{Marie-Virginie Salvia, Cécile Cren-Olivé, Laure Wiest, Robert Baudot and Emmanuelle Vulliet*}

University of Lyon, Institute of Analytical Sciences, CNRS UMR5280, TRACES Team, University Lyon 1, ENS -Lyon, 5 rue de la Doua, 69100 Villeurbanne, France

\begin{abstract}
Veterinary antibiotics and steroid hormones can be present at low levels in soil. Analytical methodologies are therefore necessary to analyse these compounds at the trace level in such a complex matrix.

The goal of this work was to compare Pressurised Liquid Extraction (PLE), which is usually used to extract drugs from soil, and a modified-QuEChERS (Quick, Easy, Cheap, Effective, Rugged and Safe) method. Furthermore, several clean-up methods were evaluated. Selective Pressurised Liquid Extraction (SPLE) and Dispersive Solid Phase Extraction (dSPE) used after PLE and QuEChERS, respectively, were tested. These techniques permit a fast and simple purification step. SPE, which is frequently used, was also evaluated. To perform this comparison, both recoveries and matrix effects were compared and the analyses were performed using liquid chromatography coupled to tandem mass spectrometry (LC-MS/MS).
\end{abstract}

SPLE and dSPE did not significantly decrease matrix effects. A tandem SPE using SAX and Strata-X cartridges offered the best efficiency. Regarding the comparison between PLE and QuEChERS, the modified-QuEChERS led to better recoveries for certain substances. No significant differences were noted in term of matrix effects. Therefore, the modified-QuEChERS method is recommended.

Keywords: Soil; Pressurised liquid extraction; QuEChERS; LC-MS/ MS; Antibiotics, Steroid hormones

\section{Introduction}

Several chemical substances are increasingly used in daily life, as well as for industrial and agricultural activities. Therefore, these compounds are being dispersed in environmental compartments. For instance, many drugs and active principles are present in the environment. These pollutants are known as "emerging contaminants". The pollutants can be defined as contaminants that have not yet been submitted to any regulation and are not necessarily persistent in the environment but are introduced continuously at low concentrations. Veterinary antibiotics and the steroid hormones are among these substances that concern the scientific community. Antibiotics are used in veterinary medicine to treat diseases but also to promote growth [1]. Steroid hormones are administered to both humans and animals for therapeutic reasons, in addition to those produced by the organism [2]. These compounds are subsequently excreted by humans and animals and pass through treatment plants where they are only partially eliminated $[1,3,4]$. Therefore, these substances are found in waters, sludge and manure spread on agricultural lands.

The dissemination of antibiotics and steroid hormones into the environment can have adverse effects over time. Indeed, they can induce pathogen resistance to antibiotics $[1,5]$ and be harmful to ecosystems. As for steroid hormones, some of them are endocrine disruptors and can produce effects on growth, reproduction and other finely tuned hormonally regulated processes of species [6]. Moreover, their presence is suspected to be linked to an increase of the incidence of breast and testicular cancers in humans noted in recent years [7].

Several methods have already been established to analyse veterinary antibiotics and steroid hormones in water [8-20]. However, few procedures exist for soil $[10,17,21-27]$, which is a more complex matrix, because of the presence of numerous interfering substances and the necessity of breaking interactions between target compounds and soil. Furthermore, the methodologies are generally set up for only one category of compounds, and few inter-families methods have been developed for the soil matrix. Nevertheless, detection and quantification with few steps and in a reasonable time of various chemical families in a sample is a necessity. Therefore, it is necessary to develop sensitive analytical methodologies to detect simultaneously traces of veterinary antibiotics and steroid hormones in soil.

When setting up such analytical procedures, the most difficult and time consuming task is the sample preparation step, which permits the specific extraction of target substances from soil. This step combines one or more extractions and purifications. Concerning the extraction, conventional techniques are based on either mixing the solid with an organic solvent or using a Soxhlet extraction procedure. More recently, other procedures, such as pressurised liquid extraction (PLE) [22, 2837], supercritical fluid extraction (SFE) [32], ultrasound [22,30,31,38-

*Corresponding author: Emmanuelle Vulliet, University of Lyon, Institute of Analytical Sciences, CNRS UMR5280, TRACES Team , University Lyon 1 , ENS -Lyon , 5 rue de la Doua , 69100 Villeurbanne, France, Tel: +33-4-37-42-36-08 E-mail: emmanuelle.vulliet@isa-lyon.fr

Received June 26, 2014; Accepted October 14, 2014; Published October 16 2014

Citation: Salvia MV, Cren-Olivé C, Wiest L, Baudot R, Vulliet E (2014) Comparison of Two Analytical Methods for the Determination of Traces of Veterinary Antibiotics and Steroid Hormones in Soil Based on Pressurised Liquid Extraction (PLE) and Quick, Easy, Cheap, Effective, Rugged, Safe (Modified-Quechers) Extraction Pharm Anal Acta 5: 315. doi:10.4172/2153-2435.1000315

Copyright: @ 2014 Salvia MV, et al. This is an open-access article distributed unde the terms of the Creative Commons Attribution License, which permits unrestricted use, distribution, and reproduction in any medium, provided the original author and source are credited. 
Citation: Salvia MV, Cren-Olivé C, Wiest L, Baudot R, Vulliet E (2014) Comparison of Two Analytical Methods for the Determination of Traces of Veterinary Antibiotics and Steroid Hormones in Soil Based on Pressurised Liquid Extraction (PLE) and Quick, Easy, Cheap, Effective, Rugged, Safe (Modified-Quechers) Extraction. Pharm Anal Acta 5: 315. doi:10.4172/2153-2435.1000315

40] or microwaves [31,32], have been used. In 2003, a new extraction procedure named QuEChERS (Quick, Easy, Cheap, Effective, Rugged and Safe) was described. It was initially established to extract pesticides from food matrices [41]. This extraction method is simple, rapid and requires low solvent consumption, which is an advantage in the era of green chemistry. This procedure is relatively new for the soil matrix, and only a few studies based on QuEChERS have been conducted previously on the extraction of compounds [42-45]. Very recently, we developed a modified-QuEChERS method for the extraction of antibiotics and steroid hormones from soil [46].

After the extraction, a purification step is often necessary. It can be conducted with solid phase extraction (SPE) [22,31,47,48], liquidliquid extraction (LLE) [47], gel permeation chromatography (GPC) [47] or semi-preparative liquid chromatography [47]. SPE is the most often used procedure, as it is fast, efficient and a large variety of purification sorbents is available. Moreover, it requires a low quantity of solvent and presents low risk of sample contamination. Recently, a purification technique, selective pressurised liquid extraction (SPLE), was developed. The technique involves the addition of a purification phase into the PLE cell, which thus avoids the co-extraction of interfering substances. The SPLE method was previously developed to extract PCB (polychlorobiphenyl) from sludge and organochlorine pesticides [49] and oestrogens from soil [50]. This method is rarely used for antibiotics. One application is the extraction of pharmaceuticals from a food matrix [34]. Furthermore, to the best of our knowledge, no multi-family methods using SPLE clean-up have been developed to extract both veterinary antibiotics and steroid hormones from soil.

In this context, the goals of the work described in this paper were (i) to develop a method based on PLE to extract both veterinary antibiotics and steroid hormones from soil, (ii) to compare the method with the modified-QuEChERS extraction method we previously developed and validated [46] and (iii) to evaluate SPLE, dSPE and SPE for the purification step. For these purposes, both recoveries and matrix effects were compared. The compound separation and detection were achieved with liquid chromatography-tandem mass spectrometry (LCMS/MS), which permits both sensitive and selective analyses.

Toperform thiscomparison, 11 natural or syntheticsteroidhormones were chosen. These are the natural androgens androstenedione and testosterone; the natural progestagen progesterone and the synthetic progestagens norethindrone, gestodene and levonorgestrel; the natural oestrogens oestriol, oestrone, 17 $\alpha$-oestradiol, 17 $\beta$-oestradiol and the synthetic oestrogen $17 \alpha$-ethinyloestradiol. As target veterinary compounds, the sulphonamides sulphanilamide, sulphadiazine, sulphathiazole, sulphameter, trimethoprim, sulphadimidine, sulphabenzamide, sulphadimethoxine; the macrolides erythromycin, tylosin and roxithromycin; the $\beta$-lactam penicillin $\mathrm{G}$; the antiparasitic dicyclanil and the phenicol florfenicol were chosen. Finally, six compounds that we considered as markers of human contamination were also included: sulphamethoxazole, carbamazepine, fluvoxamine, paracetamol, ibuprofen and bisphenol A.

\section{Experimental}

\section{Chemicals and materials}

Vetranal $(\mathrm{V})$ orpestanal(P) analytical standardswereusedinaddition to others that meet United States Pharmacopeia testing specifications (USP). Sulphanilamide (V), sulphadiazine (V), sulphathiazole (99\%), sulphameter $(\mathrm{V})$, trimethoprim $(\mathrm{V})$, sulphadimidine $(\mathrm{V})$, sulphabenzamide, sulphadimethoxine, erythromycin (USP), tylosin tartrate $(\mathrm{V})$, roxithromycin ( $>90 \%)$, penicillin $\mathrm{G}$ potassium salt $(\mathrm{V})$, dicyclanil $(\mathrm{V})$, florfenicol, androstenedione $(\mathrm{V})$, testosterone $(\mathrm{V})$, progesterone $(>99 \%)$, norethindrone $(\mathrm{V})$, levonorgestrel $(99 \%)$, oestriol (V), oestrone (>99\%), 17a-oestradiol (V), 17 $\beta$-oestradiol (> 98\%), 17a-ethinyloestradiol (V), sulphamethoxazole, carbamazepine (USP), fluvoxamine, paracetamol (99\%), ibuprofen (V) and bisphenol A (99\%) were purchased from Sigma-Aldrich (Saint Quentin Fallavier, France). The steroid gestodene (98\%) was purchased from AK Scientific (California, USA).

Individual stock solutions were prepared at concentrations of $200 \mathrm{mg} / \mathrm{L}$ in methanol and stored at $-23^{\circ} \mathrm{C}$. Working solutions were prepared by the appropriate mixture and dilution of the stock solutions.

Methanol $(\mathrm{MeOH})$, acetonitrile (ACN) (LC-MS grade) and acetone (HPLC grade) were purchased from Sigma-Aldrich. Pure water was obtained from a MilliQ device from Millipore (SaintQuentin-en-Yvelines, France). Formic acid (98\%, LC-MS grade), ammonium hydroxide solution (NH3, aq; $25 \%$ in water) and citric acid monohydrate were purchased from Sigma-Aldrich. Phosphoric acid (min $85 \%$ ) and sodium hydroxide were obtained from Prolabo (Paris, France). Acetic acid and anhydrous sodium salt were acquired from Arcos (Geel, Belgium).

For PLE, diatomaceous earth from Sartorius (Germany) was purchased.

QuEChERS extract tubes (AOAC method) were obtained from Agilent Technologies (Massy, France). They contain $1.5 \mathrm{~g}$ of $\mathrm{NaOAc}$ and $6 \mathrm{~g}$ of $\mathrm{MgSO}_{4}$.

The florisil phase was purchased from SDS (Peypin, France). The aluminium oxide phase was obtained from Sigma-Aldrich, and SampliQ Silica SAX SPE was purchased from Agilent Technologies. The Bondapak HC18 (Waters, Saint Quentin Yvelines, France) sorbent was also tested.

Solid-phase extractions were performed using Agilent Technologies SAX (Strong Anion eXchange) $(500 \mathrm{mg}, 3 \mathrm{~mL})$ cartridges or Phenomenex (Le Pecq, France) Strata-X (200 mg, $3 \mathrm{~mL})$ cartridges.

\section{Soil sample}

For the various experiments, a clay-loam soil that was not treated with manure or sludge was used. It contained $32.4 \%$ clay, $45.1 \%$ loam, $22.5 \%$ sand and $2.99 \%$ organic matter.

The soil sample was passed through a $3-\mathrm{mm}$ sieve to remove coarse particles. It was subsequently ground in a mortar and passed through a $0.63 \mathrm{~mm}$ sieve to obtain a homogeneous sample.

For both PLE and QuEChERS procedures, $5 \mathrm{~g}$ of soil was spiked at $50 \mathrm{ng} / \mathrm{g}$ with a $\mathrm{MeOH}$ solution containing the 31 substances. The sample was then left either 7 hours at room temperature (PLE) or one night under a nitrogen stream (modified-QuEChERS) before the extraction.

\section{Pressurised Liquid Extraction (PLE)}

PLE experiments were performed with Thermo Scientific ${ }^{\mathrm{Tm}}$ Dionex $^{\mathrm{mm}}$ ASE 200 Accelerated Solvent Extractor. An 11-mL PLE cell was filled with $5 \mathrm{~g}$ of soil and diatomaceous earth, and cellulose filters were put at the two cell extremities (Figure 1A and1B).

The extraction was performed with the following conditions: temperature of $80^{\circ} \mathrm{C}$, pressure of 120 bars, $10 \mathrm{~min}$ of static time and 2 cycles. $\mathrm{MeOH}$ was chosen as the extraction solvent. The extract was 

Veterinary Antibiotics and Steroid Hormones in Soil Based on Pressurised Liquid Extraction (PLE) and Quick, Easy, Cheap, Effective, Rugged, Safe (Modified-Quechers) Extraction. Pharm Anal Acta 5: 315. doi:10.4172/2153-2435.1000315

Page 3 of 9
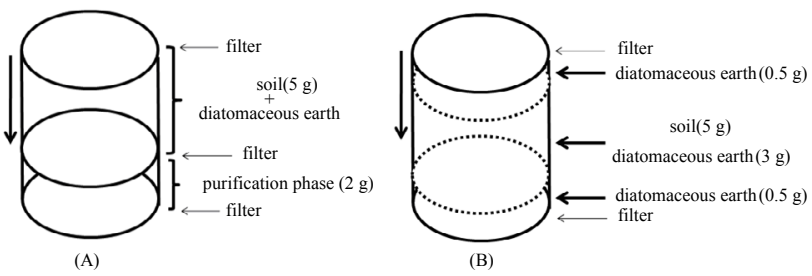

Figure 1: PLE $(A)$ and SPLE $(B)$ cell filling

subsequently evaporated to dryness under vacuum at a temperature of $40^{\circ} \mathrm{C}$ (miVac, Genevac LTD, Ipswich, England).

\section{QuEChERS extraction}

Ten millilitres of MilliQ water and $15 \mathrm{~mL}$ of ACN were added to the tube that contained the spiked soil. The tube was shaken with a vortex device (Vortex Fischer Scientific FB15013 TopMix). The AOC acetate buffer was then added, and the tube was immediately manually shaken for $30 \mathrm{~s}$ and swirled on a vortex mixer for $30 \mathrm{~s}$. The tube was then shaken for $3 \mathrm{~min}$ at $750 \mathrm{rpm}$ in a sample homogeniser (SPEX Sample Prep, 2010 GenoGrinder, Delta Labo, Avignon, France). After centrifugation at 5,000 rpm for $2 \mathrm{~min}$ (Sigma Laboratory Centrifuges $3 \mathrm{~K} 30 \mathrm{H}$, Fisher Bioblock Scientific), $10 \mathrm{~mL}$ of the ACN layer was transferred into a $12 \mathrm{~mL}$ glass tube. The extract was then evaporated to dryness under a gentle stream of nitrogen at a temperature of $40^{\circ} \mathrm{C}$.

\section{Solid Phase Extraction (SPE) clean-up}

After PLE or QuEChERS extraction, a clean-up was performed using SPE (Rapid Trace SPE Workstation, Caliper), and the clean-up involved two steps. First, after pre-conditioning of the SAX cartridge with $\mathrm{MeOH}$ and $0.04 \mathrm{M}$ citric acid, the extract (dissolved in $97 / 3$ citric acid $0.04 \mathrm{M} / \mathrm{MeOH}$ ) was passed through the cartridge at a flow rate of 1 $\mathrm{mL} / \mathrm{min}$ and recovered in a tube. Second, a Strata-X cartridge was also conditioned with both $\mathrm{MeOH}$ and $0.04 \mathrm{M}$ citric acid, and the previously recovered extract was passed through the cartridge at $1 \mathrm{~mL} / \mathrm{min}$. The Strata-X cartridge was subsequently washed with $2 \mathrm{~mL}$ of $0.04 \mathrm{M}$ citric acid and $2 \mathrm{~mL}$ of NaOAc $0.1 \mathrm{M}$. The cartridge was then dried for 30 min under a stream of nitrogen and eluted with $10 \mathrm{~mL}$ of $\mathrm{MeOH}$ at a flow rate of $1 \mathrm{~mL} / \mathrm{min}$. Finally, the recovered extract was evaporated to dryness under a gentle stream of nitrogen at a temperature of $40^{\circ} \mathrm{C}$.

The dry residue was dissolved in $200 \mu \mathrm{L}$ of $95 / 5 \mathrm{H}_{2} \mathrm{O} / \mathrm{MeOH}$ and mixed for $20 \mathrm{~s}$ prior to LC-MS/MS analysis. All of the extractions were performed in duplicate.

\section{Analysis by liquid chromatography-tandem mass spectrometry}

A HP1100 chromatographic system (Agilent Technologies) equipped with a degasser, a binary pump, an autosampler and a column oven was used. The LC system was coupled to a triple-stage quadrupole mass spectrometer 3200 QTrap (ABSciex, Les Ulis, France) with an electrospray ion (ESI) source (TurboV, ABSciex). The analytes were identified by both their chromatographic characteristics and their specific multiple reaction monitoring (MRM) fragmentation patterns. The chromatographic conditions as well as the parameters used for the detection have been previously described [46]. Figures $2 \mathrm{~A}$ and $2 \mathrm{~B}$ display chromatograms showing the separation of the 23 positively and 8 negatively ionised compounds, respectively. Data processing was performed with Analyst software (version 1.5.1).

\section{Data analysis}

To evaluate recoveries, the signal obtained for soil samples spiked at $50 \mathrm{ng} / \mathrm{g}$ (Sspiked) was compared with the signal obtained for soil extracts spiked after the sample preparation with a $\mathrm{MeOH}$ solution containing the 31 substances at the same concentration (Sref), where Sblank corresponds to the signal of a non-spiked extract of soil:

Matrix effects were determined by comparison of the signal (Sref) with the signal of the standards in a solvent (Ssolvent) at the same concentration. The matrix effect was determined with the following equation:

\section{Results and Discussion}

\section{Development of the PLE}

PLE: During the development of a method based on PLE, several parameters had to be optimised such as the temperature, the pressure, the static time and the number of cycles, as well as the nature of the extraction solvent. The solvent is the parameter that most affects the extraction efficiency [51]. Therefore, the temperature, the pressure, the static time and the number of cycles were chosen based on literature data and to optimise the extraction solvent.

Several studies have been dedicated to the extraction of antibiotics or steroid hormones from in soil using PLE.

For veterinary antibiotics, relatively low temperatures are typically used (between $70^{\circ} \mathrm{C}$ and $80^{\circ} \mathrm{C}$ ) because of the thermal degradation of some substances [28,37]. Pressures between 100 and 140 bars are usually mentioned [28,37] as well as static times between 5 and 10 minutes [37]. Finally, authors often recommend 2 or 3 cycles [28,37].

For steroid hormones, temperatures above $100^{\circ} \mathrm{C}$ (usually $120^{\circ} \mathrm{C}$ ) [52], pressures between 100 and 140 bars [52,53], a static time of 10 minutes [52] as well as 2 cycles [53] are often mentioned.

Considering all these data, the following parameters were fixed: temperature of $80^{\circ} \mathrm{C}$, pressure of 120 bars, $10 \mathrm{~min}$ of static time and 2 cycles.

With these conditions, the extraction solvent was chosen. As the studied compounds exhibit different physical/chemical properties, compromises were necessary. The solvents usually mentioned in the literature to extract veterinary antibiotics from soil are $\mathrm{MeOH}$, acetone, acetone/MeOH (50/50) mixtures, as well as $\mathrm{MeOH}$ and $\mathrm{ACN}$ mixed with aqueous solutions [28,29,31,37]. Citric acid- or phosphoric acid-based solvents are also employed to enhance the extraction of antibiotics from soil when PLE is used. The citric acid permits limiting the complexation of target analytes with cations $\left(\mathrm{Ca}^{2+,} \mathrm{Mg}^{2+}\right)$ as well as the cation exchange process, which makes it easier to extract the target compounds $[29,54]$. Citric acid is preferred to EDTA, which can precipitate in the apparatus.

For steroid hormones, solvents such as $\mathrm{MeOH}$, acetone and acetone/MeOH (50/50) mixture are the most often mentioned [52,53].

Finally, the following solvents were evaluated: acetone, $\mathrm{MeOH}$, acetone/MeOH (50/50), MeOH/ACN/0.2 M citric acid (40/40/20) adjusted to $\mathrm{pH}=4$ (with either sodium hydroxide or ammonium hydroxide) [29] and $\mathrm{MeOH} / \mathrm{ACN} /$ aqueous solution of phosphoric acid $(40 / 40 / 20)+1 \mathrm{mM}$ citric acid. For the latter solvent, different percentages of phosphoric acid in aqueous solution were tested: $0.10 \%$ $(\mathrm{pH}=3.1), 0.35 \%(\mathrm{pH}=2.8)$ and $0.875 \%(\mathrm{pH}=2.7)$. In all cases, after the 
Citation: Salvia MV, Cren-Olivé C, Wiest L, Baudot R, Vulliet E (2014) Comparison of Two Analytical Methods for the Determination of Traces of Veterinary Antibiotics and Steroid Hormones in Soil Based on Pressurised Liquid Extraction (PLE) and Quick, Easy, Cheap, Effective, Rugged, Safe (Modified-Quechers) Extraction. Pharm Anal Acta 5: 315. doi:10.4172/2153-2435.1000315
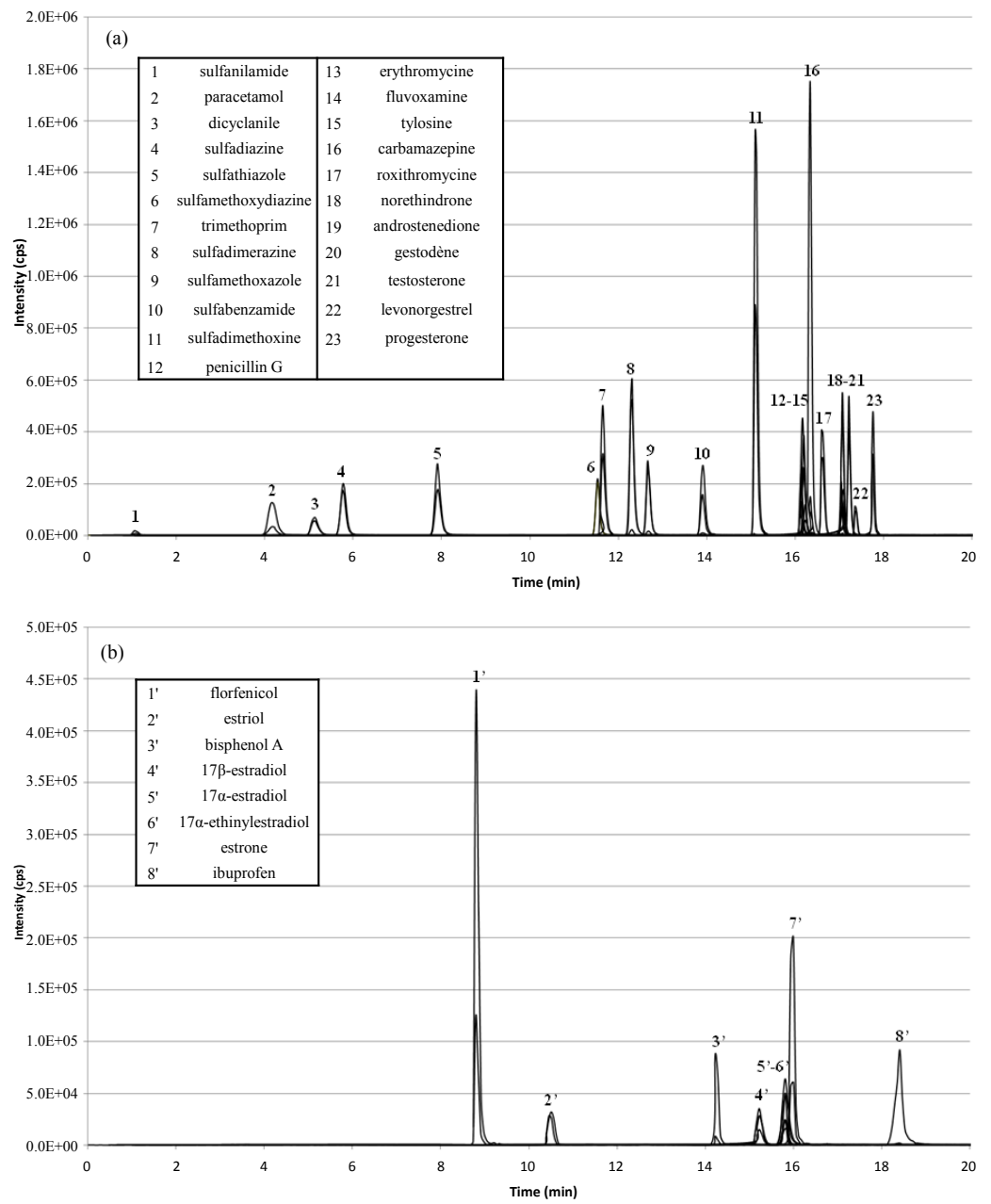

Figure 2: Chromatograms showing the separation of the (a) 23 positively ionised compounds and (b) 8 negatively ionised compounds.

PLE step, the extract was evaporated to dryness and dissolved in $1.5 \mathrm{~mL}$ of MilliQ water before the injection in LC-MS/MS.

The extraction solvent choices were evaluated for both recoveries and matrix effects. The recovery values are compiled in the table 1 .

As shown in this table, acetone was not useful for extracting antibiotics and human drugs from the soil samples. Indeed, recoveries were lower than $50 \%$ for most of the sulphonamides, lower than $10 \%$ for macrolides and penicillin $\mathrm{G}$ was not detected. For human drugs, recoveries were lower than $5 \%$ for fluvoxamine and ibuprofen. Furthermore, only $40 \%$ of paracetamol was extracted from the matrix with this solvent. Acetone was only suitable for steroid hormones, as recoveries between $70 \%$ and $80 \%$ were obtained for androgens and progestagens. As for oestrogens, they exhibited recoveries between $60 \%$ and $80 \%$.

The $\mathrm{MeOH} / \mathrm{ACN} / 0.2 \mathrm{M}$ citric acid (40/40/20) mixture adjusted to $\mathrm{pH}=4$ was also not suitable. Indeed, this mixture did not display a significant increase of recoveries compared to the other solvents tested. Moreover, this solvent led to important matrix effects: between $-70 \%$ and $-90 \%$ for most of the antibiotics and between $-60 \%$ and $-85 \%$ for steroid hormones. This could perhaps be explained by the presence of citric acid, which most likely favours the extraction of interfering substances.
Concerning phosphoric acid-based mixtures, an increase of the matrix effects was noted as the acid percentage increased. As for citric acid, phosphoric acid may induce a strong extraction of interfering compounds. As good recoveries were obtained with the mixture containing only $0.10 \%$ phosphoric acid while limiting matrix effects, the $\mathrm{MeOH} / \mathrm{ACN} / 0.10 \%$ phosphoric acid $(40 / 40 / 20)+1 \mathrm{mM}$ citric acid $(\mathrm{pH}=3.1)$ mixture was selected for further tests (mixture further designated $0.10 \% \mathrm{PA}$ ).

Thus, $0.10 \% \mathrm{PA}$, an acetone/MeOH (50/50) mixture and $\mathrm{MeOH}$ were compared. The obtained recoveries are displayed in table 1 . The results indicate that $0.10 \% \mathrm{PA}$ permitted to obtain good recoveries for veterinary antibiotics. Indeed, dicyclanil, as well as trimethoprim, had their recoveries clearly improved with this solvent. Sulphonamide and florfenicol recoveries did not vary significantly with the nature of the solvent. Most of them were included between $80 \%$ and $100 \%$. Macrolide recoveries were 1.5- to 2-fold higher with the $0.10 \% \mathrm{PA}$ solvent compared with the two others. It was also the case for penicillin $\mathrm{G}$, which was not extracted a lot with the acetone/MeOH (50/50) mixture and $\mathrm{MeOH}$.

On the other hand, the phosphoric acid-based solvent led to a huge decrease of paracetamol and bisphenol A recoveries. However, 
Citation: Salvia MV, Cren-Olivé C, Wiest L, Baudot R, Vulliet E (2014) Comparison of Two Analytical Methods for the Determination of Traces of Veterinary Antibiotics and Steroid Hormones in Soil Based on Pressurised Liquid Extraction (PLE) and Quick, Easy, Cheap, Effective, Rugged, Safe (Modified-Quechers) Extraction. Pharm Anal Acta 5: 315. doi:10.4172/2153-2435.1000315

\begin{tabular}{|c|c|c|c|c|c|}
\hline Compounds & Acetone & $\mathrm{MeOH}$ & $\begin{array}{c}\text { Acetonel } \\
\mathrm{MeOH} \\
50 / 50\end{array}$ & $\begin{array}{c}\mathrm{MeOH} / \\
\mathrm{ACN} / c i t r i c \\
\text { acid } \\
(\mathrm{pH}=4)\end{array}$ & $\begin{array}{c}\text { MeOH/ACN/ } \\
\text { phosphoric } \\
\text { acid } \\
(\mathrm{pH}=3.1)\end{array}$ \\
\hline \multicolumn{6}{|l|}{ ANTIBIOTICS } \\
\hline sulfanilamide & $46 \pm 1.6$ & $84 \pm 4.4$ & $101 \pm 20.7$ & $70 \pm 1.8$ & $73 \pm 12.1$ \\
\hline sulfadiazine & $18 \pm 0.2$ & $91 \pm 2.1$ & $90 \pm 5.0$ & $106 \pm 0.6$ & \\
\hline sulfathiazole & $19 \pm 0.3$ & $78 \pm 2.2$ & $96 \pm 4.6$ & $110 \pm 1.21$ & $2 \pm 0.7$ \\
\hline sulfameter & $37 \pm 1.3$ & $91 \pm 4.3$ & $100 \pm 8.2$ & $109 \pm 0.3$ & $2 \pm 4.1$ \\
\hline trimethoprim & $9 \pm 0.1$ & $15 \pm 0.8$ & $23 \pm 2.0$ & $79 \pm 2.4$ & $82 \pm 1.3$ \\
\hline sulfadimidine & $64 \pm 0.3$ & $90 \pm 2.3$ & \pm 2.8 & $109 \pm 1.1$ & $89 \pm 0.5$ \\
\hline sulfabenzamide & $7 \pm 0.3$ & $75 \pm 1.0$ & \pm 8.3 & $110 \pm 3.3$ & $9 \pm 2.0$ \\
\hline sulfadimethoxine & $57 \pm 1.5$ & $88 \pm 2.4$ & \pm 6.8 & $110 \pm 8.7$ & $=3.5$ \\
\hline erythromycin & $4 \pm 0.2$ & $16 \pm 2.0$ & \pm 0.6 & $40 \pm 18.8$ & $33 \pm 2.1$ \\
\hline tylosin & \pm 0.2 & $42 \pm 2.6$ & $5 \pm 7.6$ & $95 \pm 8.5$ & $86 \pm 2.9$ \\
\hline roxithromycin & $7 \pm 0.4$ & $64 \pm 2.0$ & \pm 2.3 & $100 \pm 3.8$ & $97 \pm 2.5$ \\
\hline penicillin G & nd & $6 \pm 1.4$ & \pm 0.1 & $82 \pm 1.23$ & $75 \pm 0.3$ \\
\hline dicyclanil & $60 \pm 0.1$ & $62 \pm 3.8$ & 0 & $2 \pm 1$ & $2 \pm 9.3$ \\
\hline florfenicol & $83 \pm 5.0$ & $91 \pm 6.7$ & 0 & & \\
\hline \multicolumn{6}{|c|}{ STEROID HORMONES } \\
\hline androstenedione & $75 \pm 3.0$ & $92 \pm 7.2$ & $96 \pm 8.1$ & $97 \pm 0.7$ & $99 \pm 5.6$ \\
\hline testosterone & $76 \pm 1.5$ & $112 \pm 2.8$ & $104 \pm 18.9$ & $100 \pm 3.8$ & $101 \pm 4.2$ \\
\hline progesterone & $77 \pm 1.0$ & $135 \pm 3.5$ & $117 \pm 22.9$ & $91 \pm 2.1$ & $108 \pm 13.7$ \\
\hline norethindrone & $81 \pm 0.8$ & $102 \pm 0.9$ & $109 \pm 1.4$ & \pm 5.8 & $0 \pm 4.2$ \\
\hline gestodene & $69 \pm 11.7$ & $108 \pm 14.1$ & $96 \pm 16.2$ & $100 \pm 2.5$ & $101 \pm 13.5$ \\
\hline levonorgestrel & $74 \pm 2.6$ & $98 \pm 1.6$ & $112 \pm 5.4$ & $99 \pm 2.7$ & $113 \pm 20.8$ \\
\hline estriol & $59 \pm 4.2$ & $28 \pm 1.9$ & $33 \pm 3.0$ & $20 \pm 1.8$ & $8 \pm 2.4$ \\
\hline estrone & $78 \pm 3.7$ & $89 \pm 3.4$ & $80 \pm 3.6$ & $60 \pm 2.2$ & $62 \pm 3.5$ \\
\hline 17a-estradiol & $75 \pm 1.7$ & $69 \pm 2.9$ & $73 \pm 1.0$ & $50 \pm 2.0$ & $47 \pm 2.0$ \\
\hline $17 \beta$-estradiol & $75 \pm 1.2$ & $90 \pm 3.7$ & \pm 5.2 & $0 \pm 3.3$ & $36 \pm 4.4$ \\
\hline 17a-ethinylestradiol & $69 \pm 11.0$ & $81 \pm 1.3$ & \pm 0.1 & $60 \pm$ & 0.7 \\
\hline \multicolumn{6}{|c|}{ HUMAN CONTAMINANTS } \\
\hline sulfamethoxazole & $48 \pm 0.3$ & $99 \pm 3.2$ & $102 \pm 0.8$ & $110 \pm 2.2$ & $100 \pm 3.2$ \\
\hline carbamazepine & $90 \pm 0.5$ & $99 \pm 1.9$ & $97 \pm 1.7$ & $96 \pm 1.6$ & $101 \pm 3.2$ \\
\hline fluvoxamine & $3 \pm 0.1$ & $38 \pm 2.0$ & nd & $60 \pm 1.1$ & $60 \pm 18.9$ \\
\hline paracetamol & $40 \pm 0.1$ & $18 \pm 0.4$ & $7 \pm 1.3$ & $8 \pm 0.2$ & $4 \pm 0.4$ \\
\hline ibuprofen & & & & & $98 \pm 7.7$ \\
\hline bisphenol A & $100 \pm 7.1$ & $77 \pm 5.7$ & $70 \pm 5.0$ & $42 \pm 1.7$ & $43 \pm 5.4$ \\
\hline
\end{tabular}

Table 1: PLE recoveries (\%) for the 31 studied compounds and for the following solvents: acetone, $\mathrm{MeOH}$, acetone/MeOH (50/50), $\mathrm{MeOH} / \mathrm{ACN} / \mathrm{citric}$ acid $(\mathrm{pH}=4)$ and $\mathrm{MeOH} / \mathrm{ACN} /$ phosphoric acid + citric acid $(\mathrm{pH}=3.1)$.

it allowed a good extraction of ibuprofen. As for carbamazepine, this compound was not affected by the solvent nature.

Finally, androgen and progestagen recoveries were not influenced by the solvent nature (included between $90 \%$ and 110\%). Oestrogens recoveries were clearly lower with the $0.10 \%$ PA mixture.

In this multi-residues and multi-families method, a compromise had to be made. As fluvoxamine may be slightly extracted only with $\mathrm{MeOH}$, and most of the oestrogens (target compounds with proved endocrine disruptive properties) displayed a slight increase of their recoveries with this solvent, and $\mathrm{MeOH}$ was finally selected as the extraction solvent.

Selective Pressurised Liquid Extraction (SPLE) clean-up: A SPLE clean-up corresponding to the incorporation of $2 \mathrm{~g}$ of purification phase at the bottom of the PLE cell was considered (Figure 1A). Experiments were conducted with or without adding the phase to evaluate the sorbent efficiency.

Different SPLE tests were performed. Phase/solvent combinations were established to associate a solvent with the phase the most adapted (according to the polarity, $\mathrm{pH}$ ) to have more chance of decreased matrix effects.

For the acetone/MeOH (50/50) mixture, florisil, silica and aluminium oxide were evaluated. They have already been used to extract oestrogens from soil with an acetone-based solvent [50]. The effect of $\mathrm{C} 18$ was evaluated with both $\mathrm{MeOH}$ and the $0.10 \%$ PA mixture. The $\mathrm{C} 18$ phase could retain apolar interferents not brought by the polar solvents. The phosphoric acid-based solvent was adjusted to $\mathrm{pH}=4$ to perform an experiment with the SAX phase. Indeed, at this $\mathrm{pH}$, the carboxylic acids functions of humic and fulvic acids are partially negatively ionised, and therefore, these acids could be retained by the SAX sorbent. In all cases, the final extract was evaporated to dryness and dissolved in $1.5 \mathrm{~mL}$ of MilliQ water before the injection in LC-MS/MS.

Concerning acetone/ $\mathrm{MeOH}(50 / 50)$ mixture, the results (Figure 3) indicate that florisil did not permit to decrease clearly matrix effects: they were still important for androgens, progestagens and oestrogens. They were only decreased slightly for penicillin G, sulphamethoxazole, carbamazepine, paracetamol and oestriol. With the silica sorbent, the same phenomenon was observed. Matrix effects were even amplified for sulphonamides and ibuprofen. Finally, the use of the aluminium oxide phase led to an increase of matrix effects of some compounds such as sulphonamides and oestrogens. Furthermore, they were not decreased for other compounds, such as progestagens and androgens.

As for the $\mathrm{MeOH} / \mathrm{C} 18$ combination, the $\mathrm{C} 18$ phase did not permit decreased matrix effects. Those obtained for sulphonamides were even increased (Figure 4).

For the $0.10 \%$ PA based solvent not adjusted to a specific $\mathrm{pH}$ the $\mathrm{C} 18$ phase did not allow reducing clearly matrix effects (Figure 5). Furthermore, the SAX phase used with the phosphoric acidbased solvent adjusted to $\mathrm{pH}=4$ induced an increase of most of the sulphonamide matrix effects. Furthermore, no reduction was observed for the other substances. At the $\mathrm{pH}$ values studied, the matrix interferents most likely exhibit more affinity for the solvent than the purification sorbent.

When sorbents were used, matrix effects were sometimes enhanced. It could be due to the extraction of a part of the purification phase, which could interfere with target analytes in the electrospray interface.

Finally, matrix effects differences between the solvents (without purification phase) were also examined (Figure 3 and 5). No obvious differences were observed. $\mathrm{MeOH}$ displayed matrix effects slightly lower for some compounds (veterinary antibiotics: dicyclanil, sulphonamides) compared with the other solvents.

In conclusion, no purification phase led to a significant decrease of matrix effects. Moreover, it was observed that recoveries were reduced with the purification sorbents. Considering all these results, the SPLE method was not adapted to the soil.

\section{PLE/QuEChERS comparison}

The goal of this part was to compare the optimised PLE method with a modified-QuEChERS extraction that had been previously developed and validated [46]. Both the PLE and QuEChERS technique developments permitted setting of the parameters, particularly the nature of the extraction solvent. Thus, $\mathrm{MeOH}$ was retained for PLE, whereas ACN was considered as the most adapted solvent for the modified-QuEChERS extraction. However, the rapid and simple purification methods SPLE and dSPE for PLE and QuEChERS, 
Citation: Salvia MV, Cren-Olivé C, Wiest L, Baudot R, Vulliet E (2014) Comparison of Two Analytical Methods for the Determination of Traces of Veterinary Antibiotics and Steroid Hormones in Soil Based on Pressurised Liquid Extraction (PLE) and Quick, Easy, Cheap, Effective, Rugged, Safe (Modified-Quechers) Extraction. Pharm Anal Acta 5: 315. doi:10.4172/2153-2435.1000315

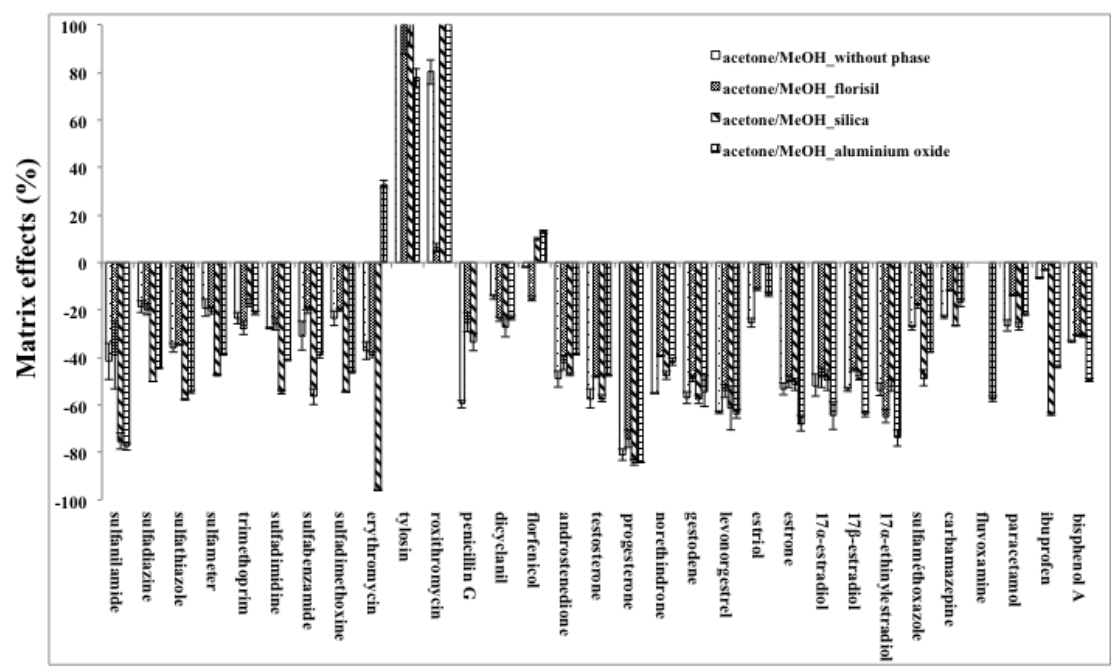

Figure 3 : Matrix effects (\%) of the 31 studied compounds during the tests performed with an acetone/MeOH (50/50) mixture.

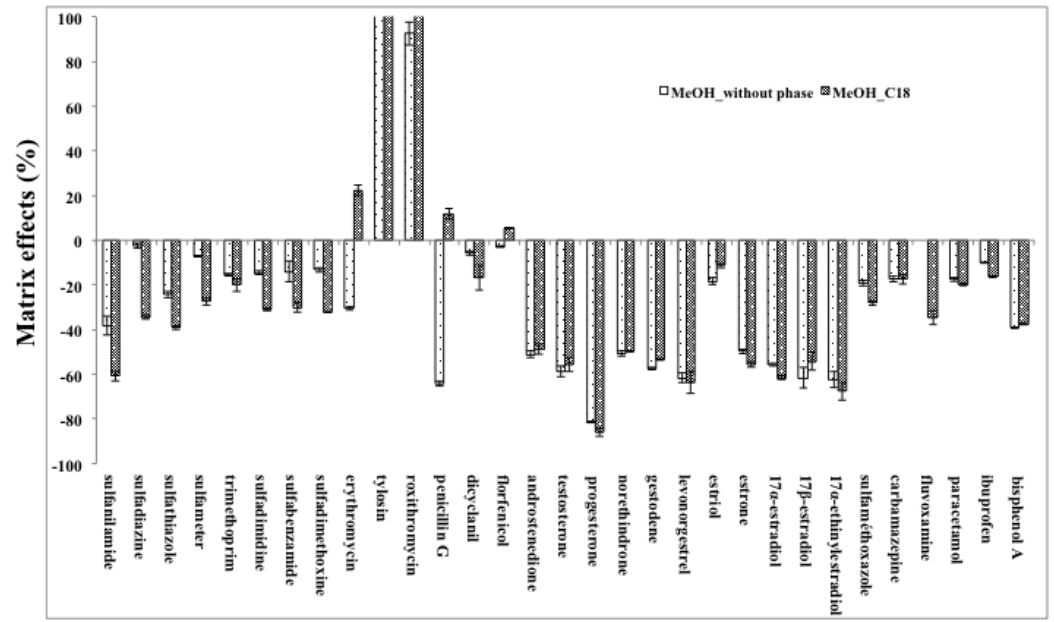

Figure 4: Matrix effects (\%) of the 31 studied compounds during the tests performed with $\mathrm{MeOH}$.

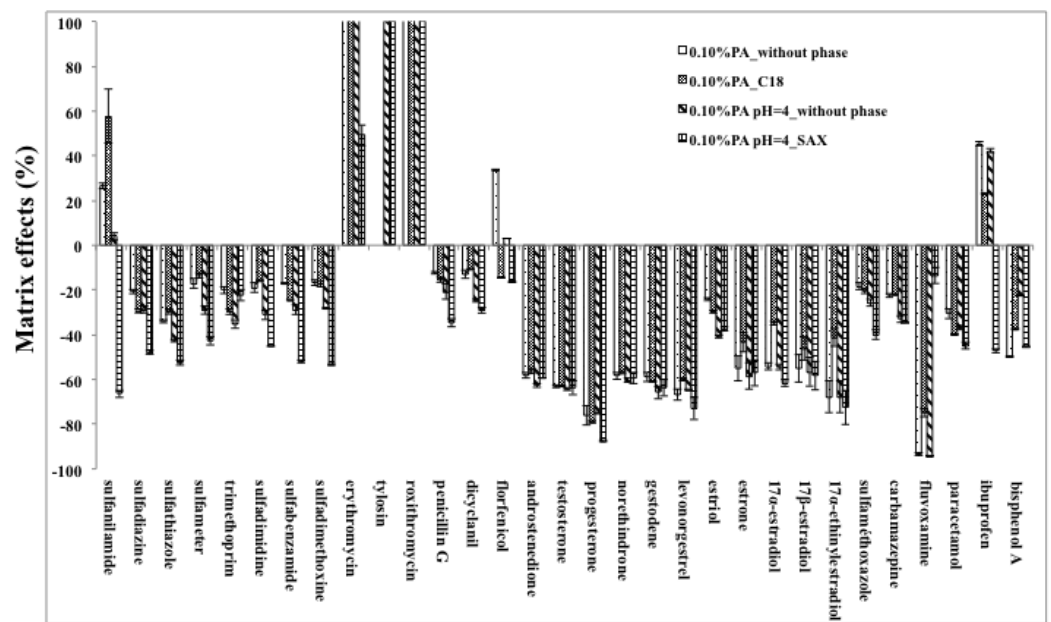

Figure 5: Matrix effects (\%) of the 31 studied compounds during the tests performed with $0.10 \%$ PA-based solvent. 
Citation: Salvia MV, Cren-Olivé C, Wiest L, Baudot R, Vulliet E (2014) Comparison of Two Analytical Methods for the Determination of Traces of Veterinary Antibiotics and Steroid Hormones in Soil Based on Pressurised Liquid Extraction (PLE) and Quick, Easy, Cheap, Effective, Rugged, Safe (Modified-Quechers) Extraction. Pharm Anal Acta 5: 315. doi:10.4172/2153-2435.1000315

Page 7 of 9

respectively, were not efficient in the reduction of matrix effects. It was therefore necessary to use a purification step with SPE cartridges.

A method consisting of tandem SPE clean-up using both SAX and Strata-X cartridges was optimised [46]. Good recoveries were obtained (between 60 and $90 \%$ for most of the compounds). Furthermore, the substances exhibited reasonable matrix effects: lower than $-40 \%$ for most of the analytes and between -20 and $-60 \%$ for steroid hormones (most of them were lower than -50\%). This SAX+Strata-X purification was applied to the extracts obtained by both PLE and QuEChERS. The efficiencies of the two whole protocols were compared. Their recoveries are displayed in Figure 6. In the case of the sulphonamides, androgens, progestagens and oestrogens, florfenicol and some human contaminants such as carbamazepine, ibuprofen, bisphenol A, the recoveries obtained with both PLE and modified-QuEChERS were comparable. However, some substances displayed better recoveries with modified-QuEChERS extraction: trimethoprim, macrolides (tylosin and roxithromycin), penicillin G, dicyclanil, oestriol, fluvoxamine and paracetamol. This observation can be explained by the fact that PLE requires a high temperature. A part of the compounds would is perhaps degraded when PLE is used, which could explain the lowest recoveries being found with this technique. Indeed, the degradation of veterinary antibiotics as well, as oestriol, when extraction is performed at high temperature has been previously mentioned in the literature $[55,56]$. In short, modified-QuEChERS produced the best results in term of recoveries.

Matrix effects were also compared (Figure 7). For most of the compounds, matrix effects were comparable with the two extraction methods. Nevertheless, it was observed that when PLE was employed, matrix effects were slightly lower for some sulphonamides and slightly higher for steroid hormones. In conclusion, the PLE and modifiedQuEChERS methods are equivalent in terms of matrix effects. Taking into account both recoveries and matrix effect results, the modifiedQuEChERS method is recommended.

\section{Conclusions}

It was demonstrated that as dSPE for the QuEChERS extraction, SPLE allowing a simple and rapid clean-up was not adapted to the purification of soil extracts containing veterinary antibiotics and steroid hormones. Therefore, a tandem SPE using both SAX and Strata-X cartridges was employed.

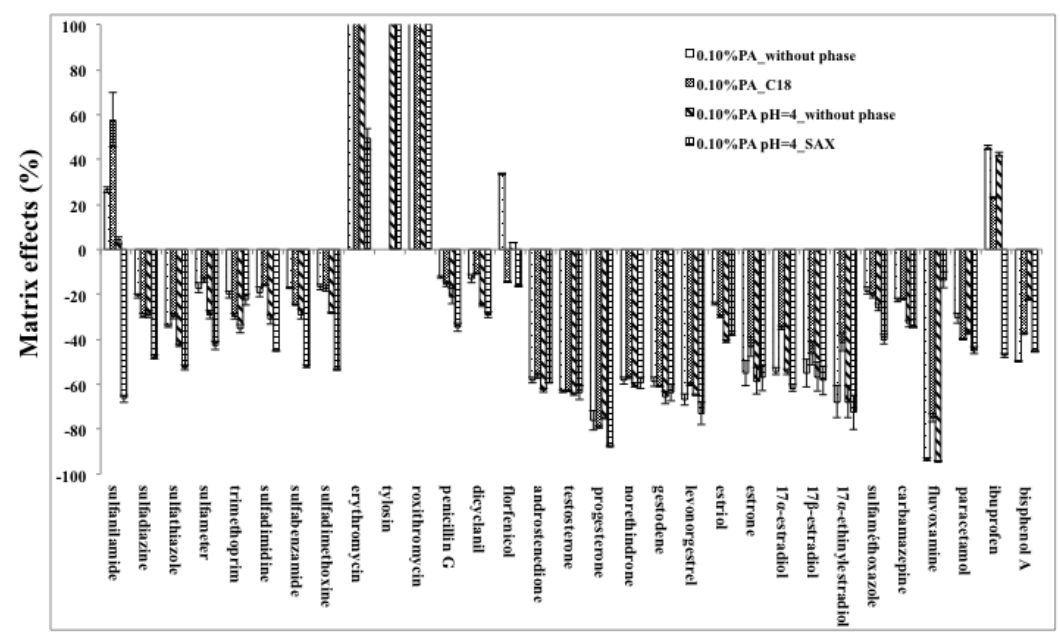

Figure 6: Recoveries (\%) for PLE and QuEChERS extractions followed by the SAX+Strata-X purification for the 31 studied compounds.

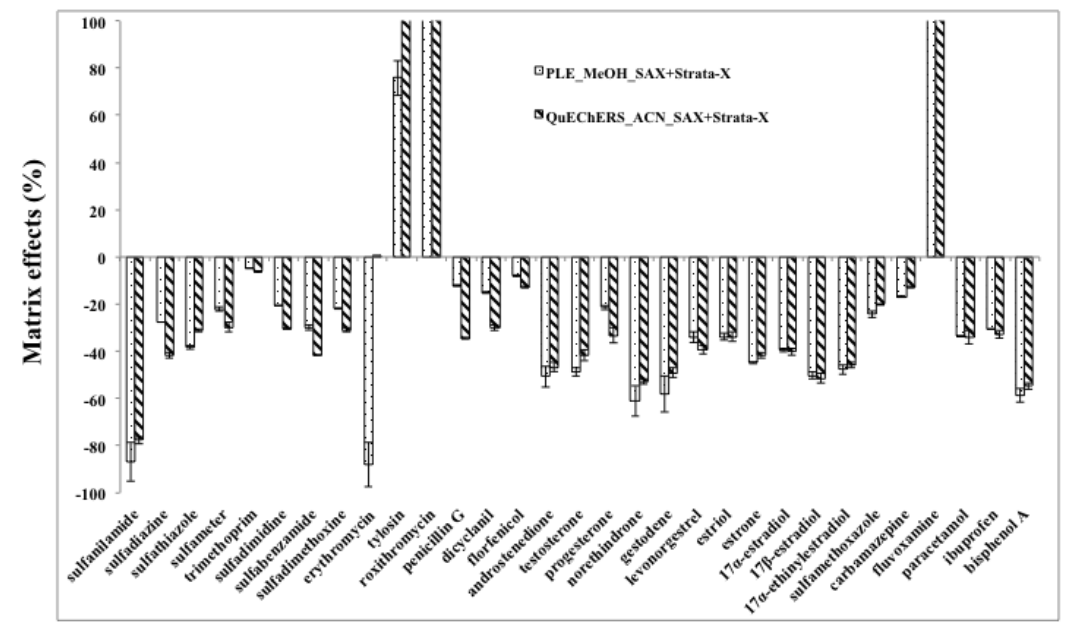

Figure 7: Matrix effects (\%) for PLE and QuEChERS extractions followed by the SAX+Strata-X purification for the 31 studied compounds 
Citation: Salvia MV, Cren-Olivé C, Wiest L, Baudot R, Vulliet E (2014) Comparison of Two Analytical Methods for the Determination of Traces of Veterinary Antibiotics and Steroid Hormones in Soil Based on Pressurised Liquid Extraction (PLE) and Quick, Easy, Cheap, Effective, Rugged, Safe (Modified-Quechers) Extraction. Pharm Anal Acta 5: 315. doi:10.4172/2153-2435.1000315

The PLE/QuEChERS comparison revealed that the modifiedQuEChERS extraction is the most adapted procedure for the examined type of multi-residues and multi-families analysis. Indeed, this technique permitted obtaining of higher recoveries for some substances compared with PLE. Moreover, this method is easier to set up, more rapid and cheaper than PLE, which requires a substantial investment. Furthermore, the PLE cell preparation is time consuming compared with the QuEChERS methodology. In this work, it was demonstrated that in certain cases, the QuEChERS method, which is relatively innovative for soil matrix analysis, is superior to the standard PLE method.

Furthermore, setting up a modified-QuEChERS extraction will allow the analysis of a large number of soil samples rapidly. This method will facilitate large-scale screening of soils.

\section{Acknowledgment}

The authors would like to thank the CNRS (Centre National de la Recherche Scientifique) for M-V.S.'s doctoral-stage funding and the ADEME (Agence de l'Environnement et de la Maîtrise de l'Energie) for the ARCOS program funding $\left(n^{\circ} 1094\right.$ C 0076).

\section{References}

1. Kumar K, Gupta SC, Chander Y, Singh AK (2005) Antibiotic use in agriculture and its impact on the terrestrial environment. Advances in Agronomy 87: 1-54.

2. Audy MC, Vacher P, Duly B (1996) 17 beta-estradiol stimulates a rapid Ca2+ influx in LNCaP human prostate cancer cells. Eur J Endocrinol 135: 367-373.

3. Schlüsener MP, Bester K (2008) Behavior of Steroid Hormones and Conjugates During Wastewater Treatment - A Comparison of Three Sewage Treatment Plants. Clean - Soil, Air, Water 36: 25-33.

4. Xu W, Zhang G, Li X, Zou S, Li P, et al. (2007) Occurrence and elimination of antibiotics at four sewage treatment plants in the Pearl River Delta (PRD), South China. Water Res 41: 4526-4534

5. van den Bogaard AE, Stobberingh EE (2000) Epidemiology of resistance to antibiotics. Links between animals and humans. Int J Antimicrob Agents 14 327-335.

6. Parks LG, Lambright CS, Orlando EF, Guillette LJ, Ankley GT, et al. (2001) Masculinization of female mosquitofish in Kraft mill effluent-contaminated Fenholloway River water is associated with androgen receptor agonist activity. Toxicological Science 62: 257-267.

7. Harrison PT, Holmes P, Humfrey CD (1997) Reproductive health in humans and wildlife: are adverse trends associated with environmental chemical exposure? Sci Total Environ 205: 97-106.

8. Vasquez-Roig P, Blasco C, Pico Y (2013) Advances in the analysis of legal and illegal drugs in the aquatic environment. Trends in Analytical Chemistry 50: $65-77$

9. da Silva BF, Jelic A, López-Serna R, Mozeto AA, Petrovic M, et al. (2011) Occurrence and distribution of pharmaceuticals in surface water, suspended solids and sediments of the Ebro river basin, Spain. Chemosphere 85: 1331 1339.

10. Vazquez-Roig P, Andreu V, Blasco C, Picó Y (2012) Risk assessment on the presence of pharmaceuticals in sediments, soils and waters of the Pego-Oliva Marshlands (Valencia, eastern Spain). Sci Total Environ 440: 24-32.

11. Kolpin D, Furlong E, Meyer M, Thurman EM, ZauggS (2006) Pharmaceuticals Hormones, and Other Organic Wastewater Contaminants in U.S. Streams, 1999-2000: A National Reconnaissance. Environ SciTechnol 36: 1202-1211.

12. Gros M, Petrovic M, Barcelo D (2006) Development of a multi-residue analytical methodology based on liquid chromatography-tandem mass spectrometry (LCMS/MS) for screening and trace level determination of pharmaceuticals in surface and wastewaters. Talanta 70: 678-690.

13. GrujiÄ $\mathrm{S}$, VasiljeviÄ T, LauseviÄ M (2009) Determination of multiple pharmaceutical classes in surface and ground waters by liquid chromatographyion trap-tandem mass spectrometry. J Chromatogr A 1216: 4989-5000.

14. Zuccato E, Calamari D, Natangelo M, Fanelli R (2000) Presence of therapeutic drugs in the environment. Lancet 355: 1789-1790.
15. Golet EM, Alder AC, Hartmann A, Ternes TA, GigerW (2001) Trace Determination of Fluoroquinolone Antibacterial Agents in Urban Wastewater by Solid-Phase Extraction and Liquid Chromatography with Fluorescence Detection. Analytical Chemistry 73: 3632-3638.

16. Tamtam F, Mercier F, Le Bot B, Eurin J, TucDinh Q, et al. (2008) Occurrence and fate of antibiotics in the Seine River in various hydrological conditions. Sc Total Environ 393: 84-95

17. Kümmerer K (2003) Significance of antibiotics in the environment. J Antimicrob Chemother 52: 5-7.

18. Liu S, Ying GG, Zhao JL, Chen F, Yang B, et al. (2011) Trace analysis of 28 steroids in surface water, wastewater and sludge samples by rapid resolution liquid chromatography-electrosprayionization tandem mass spectrometry. Journal of Chromatography A 1218: 1367-1378.

19. Belfroid AC, Van der Horst A, Vethaak AD, Schäfer AJ, Rijs GB, et al. (1999) Analysis and occurrence of estrogenic hormones and their glucuronides in surface water and waste water in The Netherlands. Sci Total Environ 225: 101 108.

20. Vulliet E, Cren-Olivé C (2011) Screening of pharmaceuticals and hormones at the regional scale, in surface and groundwaters intended to human consumption. Environ Pollut 159: 2929-2934.

21. Hamscher G, Sczesny S, Hoper H, Nau H (2002) Determination of persistent tetracycline residues in soil fertilized with liquid manure by high-performance liquid chromatography with electrospray ionization tandem mass spectrometry Analytical Chemistry 74: 1509-1518.

22. BeausseJ (2004) Selected drugs in solid matrices: a review of environmental determination, occurrence and properties of principal substances. Trends in Analytical Chemistry 23: 753-761.

23. Thiele-Bruhn S (2003) Pharmaceutical antibiotic compounds in soils - a review. Journal of Plant Nutrition and Soil Science 166: 145-167.

24. Shore LS, Shemesh M (2003) Naturally produced steroid hormones and their release into the environment. Pure and Applied Chemistry 75: 1859-1871.

25. Finlay-Moore O, Hartel PG, Cabrera ML (2000) 17ß-estradiol and testosterone in soil and runoff from grasslands amended with broiler litter. Journal of Environmental Quality 29: 1604-1611.

26. Vazquez-Roig P, Segarra R, Blasco C, Andreu V, Picó Y (2010) Determination of pharmaceuticals in soils and sediments by pressurized liquid extraction and liquid chromatography tandem mass spectrometry. J Chromatogr A 1217 2471-2483.

27. Azzouz A, Ballesteros E (2012) Combined microwave-assisted extraction and continuous solid-phase extraction prior to gas chromatography-mass spectrometry determination of pharmaceuticals, personal care products and hormones in soils, sediments and sludge, Sci Total Environ 419: 208-215.

28. Schlüsener MP, Spiteller M, Bester K (2003) Determination of antibiotics from soil by pressurized liquid extraction and liquid chromatography-tandem mass spectrometry. J Chromatogr A 1003: 21-28.

29. Jacobsen AM, Halling-Sorensen B, Ingerslev F, Hansen SH (2004) Simultaneous extraction of tetracycline, macrolide and sulfonamide antibiotics from agricultural soils using pressurised liquid extraction, followed by solidphase extraction and liquid chromatography-tandem mass spectrometry. J Chromatogr A 1038: 157-170.

30. O'Connor S, Aga DS (2007) Analysis of tetracycline antibiotics in soil: Advances in extraction, clean-up, and quantification. Trends in Analytical Chemistry 26: 456-465.

31. Diaz-Cruz MS, Barcelo D (2007) Recent advances in LC-MS residue analysis of veterinary medicines in the terrestrial environment. Trends in Analytical Chemistry 26: 637-646.

32. Pavlovic DM, Babic S, Horva AJM, Kastelan-Macan M (2007) Sample preparation in analysis of pharmaceuticals. Trends in Analytical Chemistry 26 1062-1075.

33. Golet EM, Strehler A Alder AC, Giger W (2002) Determination of Fluoroquinolone Antibacterial Agents in Sewage Sludge and Sludge-Treated Soil Using Accelerated Solvent Extraction Followed by Solid-Phase Extraction. Analytical Chemistry 74: 5455-5462.

34. Runnqvist H, Bak SA, Hansen M, Styrishave B, Halling-Sørensen B, et al. (2010) Determination of pharmaceuticals in environmental and biological 
Citation: Salvia MV, Cren-Olivé C, Wiest L, Baudot R, Vulliet E (2014) Comparison of Two Analytical Methods for the Determination of Traces of Veterinary Antibiotics and Steroid Hormones in Soil Based on Pressurised Liquid Extraction (PLE) and Quick, Easy, Cheap, Effective, Rugged, Safe (Modified-Quechers) Extraction. Pharm Anal Acta 5: 315. doi:10.4172/2153-2435.1000315

matrices using pressurised liquid extraction--are we developing sound extraction methods? J Chromatogr A 1217: 2447-2470.

35. Lillenberg M, Yurchenko S, Kipper K, Herodes K, Pihl V, et al. (2009) Simultaneous determination of fluoroquinolones, sulfonamides and tetracyclines in sewage sludge by pressurized liquid extraction and liquid chromatography electrospray ionization-mass spectrometry. Journal of Chromatography A 1216: 5949-5954.

36. Ferrer I, Furlong ET (2002) Accelerated solvent extraction followed by online solid-phase extraction coupled to ion trap LC/MS/MS for analysis of benzalkonium chlorides in sediment samples. Analytical Chemistry 74: 12751280.

37. Hansen M, Bjorklund E, Krogh KA, Halling-Sorensen B (2009) Analytical strategies for assessing ionophores in the environment. Trends in Analytical Chemistry 28: 521-533

38. Karci A, BalcioÄŸlu IA (2009) Investigation of the tetracycline, sulfonamide, and fluoroquinolone antimicrobial compounds in animal manure and agricultura soils in Turkey. Sci Total Environ 407: 4652-4664.

39. Blackwell PA, HoltenLützhøft HC, Ma HP, Halling-Sørensen B, Boxall AB, et al. (2004) Ultrasonic extraction of veterinary antibiotics from soils and pig slurry with SPE clean-up and LC-UV and fluorescence detection. Talanta 64: 10581064.

40. Xu J, Wu L, Chen W, Chang AC (2008) Simultaneous determination of pharmaceuticals, endocrine disrupting compounds and hormone in soils by gas chromatography-mass spectrometry. J Chromatogr A 1202: 189-195.

41. Anastassiades M, Lehotay S, Stajnbaher D, SchenckF (2003) Fast and easy multiresidue method employing acetonitrile extraction/partitioning and "dispersive solid-phase extraction" for the determination of pesticide residues in produce. J AOAC Int 86: 412-431.

42. Asensio-Ramos M, Hernández-Borges J, Ravelo-Pérez LM, RodríguezDelgado MA (2010) Evaluation of a modified QuEChERS method for the extraction of pesticides from agricultural, ornamental and forestal soils. Analytical and Bioanalytical Chemistry 396: 2307-2319.

43. Lesueur C, Gartner M, Mentler A, Fuerhacker M (2008) Comparison of four extraction methods for the analysis of 24 pesticides in soil samples with gas chromatography-mass spectrometry and liquid chromatography-ion trap-mass spectrometry. Talanta 75: 284-293.

44. Rashid A, Nawaz S, Barker H, Ahmad I, Ashraf M (2010) Development of a simple extraction and clean-up procedure for determination of organochlorine pesticides in soil using gas chromatography-tandem mass spectrometry. J Chromatogr A 1217: 2933-2939.

45. Padilla-Sanchez JA, Plaza-Bolanos P, Romero-Gonzalez R, Garrido-Frenich A, Vidal JLM (2010) Application of a quick, easy, cheap, effective, rugged and safe-based method for the simultaneous extraction of chlorophenols, alkylphenols, nitrophenols and cresols in agricultural soils, analyzed by using gas chromatography-triple quadrupole-mass spectrometry/mass spectrometry. Journal of Chromatography A 1217: 5724-5731.

6. Salvia MV, Vulliet E, Wiest L, Baudot R, Cren-Olivé C (2012) Development of a multi-residue method using acetonitrile-based extraction followed by liquid chromatography tandem mass spectrometry for the analysis of steroids and veterinary and human drugs at trace levels in soil. Journal of Chromatography A $1245: 122-133$.

47. deAlda MJL, Diaz-Cruz S, Petrovic M, Barcelo D (2003) Liquid chromatography(tandem) mass spectrometry of selected emerging pollutants (steroid sex hormones, drugs and alkylphenolic surfactants) in the aquatic environment. $J$ Chromatogr A 1000: 503-526.

48. Aga DS, O'Connor S, Ensley S, Payero JO, Snow D, et al. (2005) Determination of the Persistence of Tetracycline Antibiotics and Their Degradates in ManureAmended Soil Using Enzyme-Linked Immunosorbent Assay and Liquid Chromatography-Mass Spectrometry. J Agric Food Chem53: 7165-7171.

49. Hussen A, Westbom R, Megersa N, Mathiasson L, Björklund E (2007) Selective pressurized liquid extraction for multi-residue analysis of organochlorine pesticides in soil. J Chromatogr A 1152: 247-253.

50. Zhang Z, Rhind SM, Kerr C, Osprey M, Kyle CE (2011) Selective pressurized liquid extraction of estrogenic compounds in soil and analysis by gas chromatography-mass spectrometry. Anal Chim Acta 685: 29-35.

51. Carabias-Martínez R, Rodríguez-Gonzalo E, Revilla-Ruiz P, Hernández Méndez J (2005) Pressurized liquid extraction in the analysis of food and biological samples. J Chromatogr A 1089: 1-17.

52. Carabias-Martinez R, Rodriguez-Gonzalo E, Revilla-Ruiz P (2006) Determination of endocrine-disrupting compounds in cereals by pressurized liquid extraction and liquid chromatography-mass spectrometry Study of background contamination. J Chromatogr A 1137: 207-215.I

53. Petrovic M, Tavazzi S, Barcelo D (2002) Column-switching with restricted access pre-column packing for an integrated sample cleanup and liquid chromatographic-mass spectrometric analysis of alkylphenolic compounds and steroid sex hormones in sediment. J Chromatogr A 971: 37-45.

54. Shafrir M, Avisar D (2012) Development Method for Extracting and Analyzing Antibiotic and Hormones Residues from Treated Wastewater Sludge and Composted Biosolids. Water Air Soil Pollut 223: 2571-2587.

55. Ye V, Yang Y, Zhang J, Liu M, Hou L, et al. (2013) Simultaneous determination of steroidal and phenolic endocrine disrupting chemicals in fish by ultra-highperformance liquid chromatography-mass spectrometry/mass spectrometry. $J$ Chromatogr A 1278: 126-132.

56. Göbel AA, Thomsen A, McArdell CS, Alder AC, Giger W, et al. (2005) Extraction and determination of sulfonamides, macrolides, and trimethoprim in sewage sludge. J Chromatogr A 1085: 179-189. 